\title{
INVESTIGATING THE ACADEMIC PROCRASTINATION OF EFL STUDENTS
}

\author{
M.M Wirajaya ${ }^{1}$, N.N Padmadewi ${ }^{2}$, D.P Ramendra ${ }^{3}$ \\ ${ }^{123}$ English Language Education, Post Graduate Program, Universitas Pendidikan Ganesha, Singaraja \\ e-mail: mersandy,wirajaya184@gmail.com,nym.padmadewi@undiksha.ac.id, putu.ramendra@undiksha.ac.id
}

Procrastination is frequently performed by students and many studies claimed that it happened to all levels of students. This study aimed at: (1) investigating the level of academic procrastination of EFL students in Universitas Pendidikan Ganesha, (2) investigating EFL students' reasons in engaging on academic procrastination, and (3) determining whether self-efficacy correlates with academic procrastination. An embedded mix-method with explanatory design was employed in this study, it is started quantitatively than followed up by an in-depth qualitative study. A correlational analysis was used to test the hypothesis of this study. The findings revealed that (1) EFL students in Universitas Pendidikan Ganesha mostly had a high level $(63 \%)$ of procrastination $(n=130)$; (2) the main reasons of EFL students to engage on academic procrastination were; Time management $(28 \%)$, Aversiveness of the Task (24\%), Sincerity (22\%), and Personal Initiative (26\%); and (3) there was a strong, negative correlation between students academic procrastination and self-efficacy, $r=-.651, n=130$.

\section{Keywords: Academic Procrastination; Self-Efficacy; EFL Students}

\section{INTRODUCTION}

In order to be productive, either working or non working individual are required to complete various assignments and deadlines during a day. However, the completion of these assignments are often delayed due to many factors, whether internat or external factors. This process of delaying or postponing the assignments is known as procrastination. Currently, there is no complete agreement or consensus among researchers on the definition of procrastination, as various researchers point out different aspects of behaviour. However, the concept of procrastination has developed as more research has been conducted, and therefore, deeper understanding on procrastination has been reached. The most commonly used definition of procrastination was given by Steel (2007) that is to voluntarily delay an intended course of action despite expecting to be worse off for the delay. This definition includes all three aspects of procrastination which are; delay, counter-productivity, and needlessness.

Procrastination occurs in every aspect of behavior and action but the most common type of procrastination is the one that occurrs in the academic setting which is known as academic procrastination. Bashir (2019) stated that academic procrastination is a superior usage of procrastination that happens in the educational settings. It involves perceiving that one needs to undertake an academic activity, or carry out an academic task, like as undertaking the weekly reading assignments, finishing a school related project, preparing for exams, or writing a term paper, as a matter of fact failing to encourage oneself to do so within the probable time frame (Ackerman \& Gross, 2005).

Research has revealed that academic procrastination is a very common event among students especially university level students. Steel (2007) discovered that almost all occasionally procrastinate in one or another domain of their studies, and approximately every second student regularly procrastinates. Similiarly, Ellis and Knaus (1977) measured that around $95 \%$ of students procrastinate on their educational tasks. In addition, Schouwenburg (1993) discovered that more than $70 \%$ of college students were procrastinate on a regular basis and about $20 \%$ of them reported chronical procrastination.

Since procrastination may have a strong negative impact on students' academic success, it is necessary for educators to prevent students to procrastinate in order to help 
them to gain success in their academic achievement. In fact, the majority of procrastinate students also shown an intention to reduce their procrastination (Solomon \& Rothblum, 1984). In order to achieve the goal of preventing students' to procrastinate, it is essential to understand the level of students' academic procrastination and what may causes it. Therefore, this present study is intended to examine the academic procrastination level of university students particularly those students who are learning a foreign language, or in this case English language learners. This study is also intended to investigate EFL students' reason in engaging such behaviour.

Learning a foreign language requires a lot of dedication and hard work, especially when students do not live in a country in which the target language is the medium of communication that is regularly used. As with English language students in Indonesia, students do not find the opportunity to communicate and practise their language skills very often. In order to improve their skills, students are required to complete many tasks such as reading texts on various levels, performing speaking activities in and outside of the classroom, listening to audio materials or writing essays in English. Since language learning requires the fulfilment of such a large number of assignments, an examination of the procrastinatory behaviors of language learners become important.

One of the most common predictors of academic procrastination is self-efficacy. Bandura (1995) explains that self-efficacy refers to someone's beliefs in his/her capabilities to organize and execute the courses of action required to manage upcoming situations. People with high self-efficacy will normally see difficult tasks and assignments as something to be mastered instead of something to be avoided. They will show determination and always manage to recover quickly from setbacks. On the contrary, people with low self-efficacy usually will avoid challenging tasks, they believe that they are incapable to perform such tasks and will focus on negative outcomes. Since procrastinators often have problems setting goals for themselves, it is believed that people with low levels of self-efficacy are more procrastinate rather than those who are highly efficacious.

Several Previous studies have found that self-efficacy plays a big role in academic procrastination. Steel (2007) discovered that self-efficacy is a strong and regular predictor of procrastination after investigating 216 different studies. It was believed that fear of failure had a strong association with low self-efficacy and procrastination. In line with this study, Van Eerde (2003) conducted a meta-analysis study on 104 previous published articles using student populations. The aim of this study is to find the relationship of several different variables with procrastination. Self-efficacy was one of the variables being observed. Negative self-efficacy was found to be an important variable in relation to procrastination across the studies. In addition, Haycock, McCarthy, and Skay (1998) conducted a study which asked students to imagine writing a paper, for example, and to rate their efficacy for the task. They found that students who were low in self-efficacy procrastinated more. It indicates that the lower someone's self-efficacy, the higher their levels of procrastination.

Despite many studies conducted previously on procrastination, there has been no research conducted on the topic involving the education university in Bali like The Ganesha University of Education (Universitas Pendidikan Ganesha). Moreover, based on an informal interview conducted with some students enrolled at English Language Education of Universitas Pendidikan Ganesha, it was revealed that students tend to procrastinate tasks that they believe they can complete regardless of the difficulty of the task, they decided to delay to complete the task until the very last minute of deadline; and according to them, their work qualities does not suffer from postponing. This implies that students with high level of self-efficacy are more procrastinate. With regard to this, Saddler and Buley (1999) revealed that self-efficacy for learning and performance was not a significant predictor of academic procrastination. Due to this occurrence and also the scarcity of the research on the topic conducted in Indonesia, more studies are needed. Therefore, the aim of the present study is to investigate how the self-efficacy correlates-with academic procrastination.

\section{RESEARCH METHOD}

This current study used an explanatory design that belongs to an embedded mixmethod since qualitative data help build upon initial quantitative results and the researcher places greater emphasis on the quantitative methods than the qualitative methods. 
The sample of this present study was taken by using purposive sampling method. The criteria for taking the sample were the students need to be at least at their $7^{\text {th }}$ semester. This consideration is applied due to the probability of this students to be at college for long enough to experience academic procrastination compare with students below their semester.Therefore, there were 130 students (Class A, B, D, E) of the $7^{\text {th }}$ semester enrolled in English Language Education Program of Universitas Pendidikan Ganesha which taken as sample in this study.

The data were collected through questionnaires in form of students' academic procrastination (PASS) adopted from Solomon \& Rothblum (1994) and self-efficacy scores developed by Bashir (2019). In addition, group discussion was conducted to obtain the qualitative data supporting the quantitative data.

The data analysis involved descriptive and inferential analysis. Descriptive analysis aims at describing data by measuring mean, median, mode, range, variance, and standard deviation. Futhermore, the descriptive analysis of PASS on ideal mean (Mi) and ideal standard deviation (SDi) became a medium to divide participants into level of academic procrastinators. Meanwhile, inferential analysis by using correlational analysis aims at testing hypothesis. Additionally, the qualitative data were analyzed by using Miles and Huberman Model.

\section{FINDINGS AND DISCUSSION}

The data of students' academic procrastination were divided into two parts namely; areas of procrastination and reasons of doing procrastination. Descriptive analysis was applied in order to know the level of students' academic procrastination. The summary of the students' academic procrastination is demonstrated in the following Table 1.

Table 1. The Summary of Students' Academic Procrastination Level

\begin{tabular}{|c|c|c|c|c|c|c|c|c|}
\hline & $\mathbf{N}$ & Range & Min & Max & Sum & Mean & Std. Deviation & Variance \\
\hline Level & & & & & & & & \\
\hline $\begin{array}{l}\text { Students' } \\
\text { academic } \\
\text { procrastination }\end{array}$ & 130 & 46 & 127 & 173 & 19605 & 150.81 & 13.12 & 172.25 \\
\hline $\begin{array}{ll}\text { Valid } & \mathrm{N} \\
\text { (listwise) } & \end{array}$ & 130 & & & & & & & \\
\hline
\end{tabular}

In order to determine the category of the students' academic procrastination level, the Mean Ideal (Mi) and Standard Deviation Ideal (SDi) were based on its ideal maximum and minimum score. Based on the calculation, the categorization of the students' academic procrastination level was classified into four categories as presented in Table 2.

Table 2. The Distribution of Students' Academic Procrastination Level

\begin{tabular}{|c|c|c|c|}
\hline Category & Interval & $\mathbf{F}$ & Percent \\
\hline Very High & $\geq 161$ & 37 & $28 \%$ \\
\hline High & $132-160$ & 82 & $63 \%$ \\
\hline Low & $103-131$ & 11 & $9 \%$ \\
\hline Very Low & $<103$ & $\begin{array}{c}0 \\
130\end{array}$ & $\begin{array}{c}0 \% \\
100 \%\end{array}$ \\
\hline
\end{tabular}

Table 2. reveals that students of $7^{\text {th }}$ semester had several levels of procrastination. It was discovered that the students in the very high level with the total score at 167 and above were 37 students, with $28 \%$ from overall $100 \%$. The students' on a high level of procrastination with the total score ranged from 132 - 160 were 82 students, with $63 \%$ from overall $100 \%$. 11 students categorized into a low level of procrastination, with the total score ranged from $103-131$ and were counted as $9 \%$ from a total of $100 \%$. In this present study, from 130 students, there were no students who were categorized into a very low level of academic procrastination.

Hence, the result of the descriptive analysis inferred that the students of the $7^{\text {th }}$ semester tended to do procrastination because mostly the students had a high level of 
academic procrastination. This is supported by Kármen et al., (2015) that based on recent studies, $70 \%$ of university students thought that procrastination in the academic situation is a very common phenomenon and believes that procrastination as characteristic of their academic activities. Argiropoulou and Ferrari (2014) also affirm that over $75 \%$ of university students procrastinate frequently, particularly towards meeting study obligations, and it was reported that the students delay their tasks due to academic difficulties. Moreover, Solomon and Rothblum (1994) assert that university students tend to procrastinate to a great extent, especially when it comes to tasks most closely related to their academic performance.

Besides, Ellis and Knaus (1977) also found that estimates around $80 \%$ to $90 \%$ of undergraduate university students report that they experience procrastinations during their academic life. Clark and Hill (1994) argue that between $30 \%$ and $45 \%$ of 184 American undergraduate students reported problems with procrastination. Schouwenburg (1993) affirms that from 278 undergraduate students in Netherland, found over $70 \%$ of students reported engaging in academic procrastination, and $20 \%$ of the students reported chronic academic procrastination. Recently, Klassen, Krawchuk, and Rajani (2008) reported that $58 \%$ of their undergraduate students spending three hours or more per day in procrastination. More recently, Özer and Saçkes (2011) found that 53\% of 150 undergraduate Turkish students reported experiencing frequent academic procrastination. Thus, academic procrastination is a significant problem for undergraduate students all over the world.

University students' academic life requires them to put their effort and attention in every moment. They need to devote their time mostly on completing various tasks such as attending several classes in a day, submitting assignments, engage in a group discussion whether online or offline, submitting projects at the end of the semester, and joining in several extracurricular activities with several obligations. Students tended to engage in procrastination as they have many tasks to do and should be completed in a short period. This finding is supported by Mandap (2016) that procrastination is very common in the university where the students have a multitude of academic requirements such as examinations, assignments, and research works. Futher, Khan, Arif, Noor, and Muneer (2015) believe that academic procrastination is a prevalent problem among university students, who are faced with several activities on their academic tasks, such as a multitude of examinations, term papers, and project. Rothblum, Solomon, and Murakami (1986), and Steel (2007) also agree that university students tend to procrastinate in one or another domain of their studies, and they tend to regularly procrastinate.

In regards to their success in academics, the students need to regulate their learning so that the academic requirements are fulfilled. But, with numerous activities and requirements, students sometimes experience difficulties to arrange their activities well. As a result, the students tend to delay their tasks, as they choose to complete the task with the nearest deadline first or choose the most important activities to be done first. This activity then makes the students engage in procrastination on and on. This is supported by Bakar and Khan (2016) that university students are required to devote their time mostly on completing several requirements on their academic life. They also assert that sometimes selfregulation of learning, which is prime importance for a higher learner, does not seem to be ready enough, and make the students having difficulties to regulate their academic activities so that they tend to procrastinate on several tasks.

Moreover, with the numerous amount of tasks that should be accomplished in a certain period, the students sometimes lose their motivation in completing the tasks and have no initiative to complete the tasks. Ackerman and Gross (2005) further affirm that procrastination dominates all aspect of human life, but mostly occur in the academic life, due the students need to complete one task or more tasks in a period, for example solving a term paper, preparing for exams, completing a class project or concluding a reading assignment, but lacking in motivation to do in a specified period. This is also supported by Malkoç and Mutlu (2018) that the university students need to carry out an academic task or undertake academic activities, such as writing a term paper, studying for an examination, finishing a school-related project, but one reason or another, failing to motivate oneself to do so within the expected time frame. 
As for the reason of EFL students to engage on academic procrastination, the data were obtained from the second part of Procrastination Assessment Scale for Students (PASS). It was about reasons of doing a procrastination. There were 26 items included in reasons of doing procrastination that related to time management, aversiveness of the task, sincerity, and personal initiative. The summary of the students' reasons in doing procrastination including mean, minimum, maximum, sum, and percentage were presented in Table 3.

Table 3. The Summary of Students' Reasons in doing Procrastination

\begin{tabular}{ccccccc}
\hline Statistics Reasons & N & Mean & Min & Max & Sum & Percentage \\
\hline Time management & 130 & 3.65 & 2 & 5 & 474 & $28 \%$ \\
Aversiveness of the Task & 130 & 3.21 & 2 & 4 & 417 & $24 \%$ \\
Sincerity & 130 & 2.98 & 2 & 4 & 387 & $22 \%$ \\
Personal Initiative & 130 & 3.43 & 3 & 5 & 446 & $26 \%$ \\
& & & & Total & 1724 & $100 \%$ \\
\hline
\end{tabular}

The above table showed that the students' reasons of doing procrastination are mostly related to the time management. It was showed by its percentage of $(28 \%)$ which was the highest among other reasons. Personal initiative (26\%) and Aversiveness of the task $(24 \%)$ are also a common reasons for students'to engage on academic procrastination. Meanwhile, the lowest reason of procrastinating was sincerity $(22 \%)$. These four reasons became the main reasons for students' procrastination, due to only a little difference in the percentage.

In time management domain, there are five reasons that the students could choose to represent their reasons for their time management. From 130 students, $22 \%$ of the students choose that they like to challenge themselves off waiting until the deadline approaches. $22 \%$ of students choose that they feel it takes too much time to write the term paper, and they also have many other things to do. $18 \%$ of students choose that they engaging in procrastination due to they know that their classmates have not started the paper yet. The last $17 \%$ of the students choose to wait for their friends and looking for advice. In this case, they waited for their friend first, as their friendship begins to work on the paper, they also start to work on their paper.

Moreover, the result of the group discussion revealed that students like to delay working on the assigned task and wait until the deadline coming up. This group discussion also revealed that the students like doing their paper in the last minutes as they can be more focus on what they are doing, they think better within the limited time, and it helps them in boosting their ideas. When the students started to work on the given assignment two or three days before the due date, they tended to be more easily distracted by something else around them. The students also tended to be a procrastinator as they know that they will get the things done, no matter when and how, and the belief that they can finish the task and submit the task on time.

It can be inferred that the students tended to procrastinate as they will get better ideas, think better, focus more on the task, devote their learning, and know that they can do the task, whenever they work under a limited amount of time. These findings supported by Schraw, Wadkins, and Olafson (2007) and Van Eerde (2003) that students usually concentrate better on a task that they have under a limited amount of time. Some of the students intentionally plan to procrastinate in order to get the benefits of doing procrastination, which is to work more effectively. When the students work within a limited time, they seemed to have better control and use of time, they will show strong motivation in getting the things done, and increase their self-confidence in completing the task.

The second reason of procrastination is related to the aversiveness of the tasks. This reason is related to the value of the task itself to the students. Based on the result of the questionnaire, in terms of the aversiveness of the task, the students mostly feel uneasy to write a term paper. This is supported by the result of the group discussion. The students admitted that they sometimes think about whether or not the lecturer likes their work. As they think about it too much, they lose their desire to continue working on their paper. The students also admitted that they faced problems with what they should write on the paper. 
This is usually about what they should include or not included in their paper, and they became overwhelmed by the task itself. The students mostly faced problems whenever the task is about writing. The students believe that writing is not an easy task, as they need to be more detailed and clear on discussing the topic so that the reader can understand the writing easily and avoiding misunderstanding. The students further admitted that they were unable to choose one of the various topics provided. Hence, they feel frustrated, confuse, and choose to put off their work, and wait until they get better ideas in choosing the topic.

The third reason for engaging in procrastination is related to sincerity. Sincerity is related to the students' dedication, seriousness, and focus while working on their tasks. If the students are not sincere towards their tasks, the students can be easily distracted by external factors or circumstances. In this dimension, there are eight items that can be chosen by the students. $15 \%$ of 130 students think that they did not know enough to write the paper, therefore they were not sincere to do their task. Besides, the students choose they were pressured by friends to do other things (14\%), they have no trust on their self to do a good job $(13 \%)$, they did not have enough energy to begin the task $(12 \%)$, they resent people to set deadlines for them (12\%), they mostly concern on other's expectation on the result of their work (12\%). Besides, they also concern about their expectation and classmates' judgment. These are the reason for the students to engage in procrastination, as they can not focus on their tasks, they easily distracted by external factors.

This is supported by the result of the group discussion. The students admitted that they easily distracted by something else or external factors, such as notification of social media or shot messages from their friend. This group discussion also revealed that the students concern about other's judgment and comments, such as judgment from their classmates and lecturer. It makes them sometimes doubt themselves, whether or not they could finish the task.

The last reason for students engaging in procrastination is related to the students' initiative. Personal initiative means the students' pro-active and self-starting approach to carry on completing the assigned tasks and persistently working to overcome setbacks and barriers. When the students are working on the assigned tasks, they need to have a good self-starting to avoid procrastination and persistently working on it. Based on the result of the questionnaire, in terms of the personal initiative, the students mostly choose that they set a very high standard of the task, but at the same time worrying that they would not be able to meet the set standard.

This is supported by the result of the group discussion. The students admitted that they set a high standard of what their work would be, but at the same time they worry about their ability to meet those standards. This group discussion also revealed that the students tended to wait until the deadline coming, they have greater excitement whenever they can finish the task on time within a limited amount of time. The students also admitted that they faced problems in requesting information from other people, including their lecturer. They tended to wait for information about the paper assigned by the lecturer because sometimes they feel uncomfortable approaching the lecturer even though there is some information related to the paper that they need to ask the lecturer. Lastly, the students admitted that they feel too lazy to write a term paper so that they tended to delay their work and just wait until the deadline is near.

Moreover, besides revealing the level of students' academic procrastination, the result of the questionnaire also showed area of academic procrastination that the students mostly engaged on. The descriptive analysis of academic procrastination areas was summarized in the following figure.1
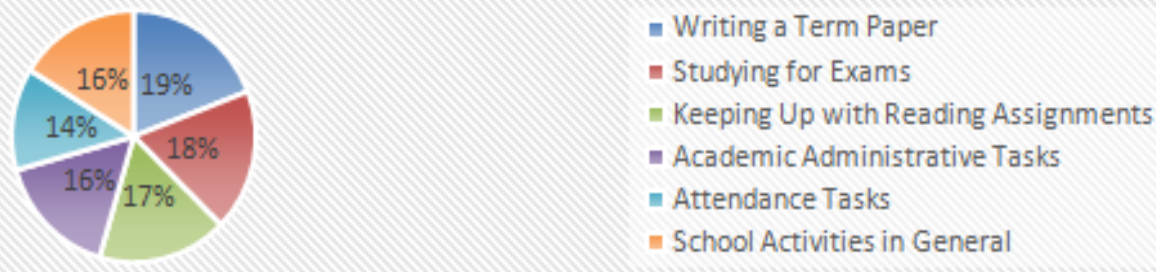

Figure 1. The Chart of Students' Academic Procrastination Areas 
Figure 1 . showed that $19 \%$ of the students mostly procrastinate on writing a term paper, followed by $18 \%$ of the students procrastinate on studying for exams, $17 \%$ students procrastinate on keeping up with reading assignments, $16 \%$ of the students procrastinate on academic administrative tasks and school activities in general, and $13 \%$ students procrastinate on attendance tasks.

This finding is supported by the result of a research conducted by Solomon and Rothblum (1994) that undergraduate students procrastinated more often when writing a term paper with $46 \%$ than reading weekly assignments with $30 \%$, and studying for examinations with $28 \%$. Balkis and Duru (2017) found that the task that were mostly procrastinated by the students was reading weekly assignments where $45.7 \%$ of participants reported to procrastinate on this task. The second task most procrastinated was writing a term paper, where $30 \%$ of participants reported to procrastinate on this task. Moreover, Ellis and Knaus (1977) found that the majority of the participants reporting procrastinating on tasks like writing a term paper and reading weekly assignments. $30 \%$ of participants reporting to procrastinate on reading weekly assignments and $20 \%$ reporting to procrastinate on writing a term paper. Besides, Argiropoulou and Ferrari (2014) also found that reading weekly assignments with $23.5 \%$ of the participant were procrastinate on this task. $19.2 \%$ of the participants reported procrastinate on writing a term paper, $14.3 \%$ procrastinate on course attendace. On the contrary, only $12.4 \%$ and $12.8 \%$ of the students were high procrastinators in completing academic administrative tasks abd school activities in general, respectively.

In order to answer the last question on the correlation between the students' academic procrastination with self-efficacy, the correlational analysis was conducted by using Pearson Product Moment correlation coefficient. This correlation analysis provides a numerical summary of the direction and the strength of the linear relationship between two variables. Pearson correlation coefficients $(r)$ can range from -1 to +1 . The sign in front indicates whether there is a positive correlation (as one variable increases, so does the other) or a negative correlation (as one variable increases, the other decreases).

A simple bivariate correlation was employed in this study. This simple bivariate correlation means testing the correlation only between two variables. A prerequisite analysis was conducted prior to the correlational analysis to find out the normality and the linearity of the two variables. The normality test shows that the data of the two variables were normally distributed, as the Sig. value exceeds the value .200. Further, the linearity test shows that there is a relationship between students students' procrastination and students' self-efficacy belief, with the linearity value shows .368 which is higher than .05 . The correlational analysis result was summarized in Table 4.

Table 4. The Result of Pearson's Product Moment Correlation Correlations

\begin{tabular}{llrr}
\hline & & Students Procrastination & Self-Efficacy \\
\hline Students' & Pearson Correlation & 1 &,$- 651^{* *}$ \\
Procrastination & Sig. (2-tailed) & 130 &, 000 \\
& $N$ &,$- 651^{* *}$ & 130 \\
Self-Efficacy & Pearson Correlation &, 000 & 1 \\
& Sig. (2-tailed) & 130 & 130 \\
& $\mathrm{~N}$ & &
\end{tabular}

${ }^{* *}$. Correlation is significant at the 0.01 level (2-tailed).

The result of Pearson's Product Moment correlation analysis indicated that the correlation ( $r$ ) value was -.651. In which there is a negative $(-)$ sign in front of the value which indicating a negative correlation between students' procrastination and self-efficacy. Terefore, there was a strong, negative correlation between the two variables, $r=-.651, n=$ $130, p<.0005$, with high levels of students' procrastination associated with lower levels of self-efficacy belief. In addition, the result of the pearson correlation is -.651 , which when squared indicates 42,38 percent shared variance. In which self-efficacy helps to explain nearly 42 percent of the variance in responden scores on the academic procrastination.

Therefore, it can be concluded that students with low perceived self-efficacy were found to procrastinate more than those with high self-efficacy. This is consistent with the 
findings of other studies which indicated that self-efficacy was a significant behavioural construct in explaining the procrastination behaviours of the students (AlQudah, Alsubhien, \& Heilat, 2014; Chow, 2011; Hajloo, 2014; Klassen, Krawchuk, \& Rajani, 2008).

The negative correlation between academic self-efficacy and academic procrastination was consistent with previous studies. The results revealed that self-efficacy is a strong predictor of academic procrastination. These studies suggest that low self-efficacy is the main reason for procrastination. Low self-efficacy and high procrastination have strong associations with fear of failure, but regardless of this factor, self-efficacy has a direct connection to procrastination and performance. This is supported by the theory of Schraw et al. (2007) that identified low self-efficacy as possible antecedents for procrastination. Procrastination is thus a high possibility for a person who is not confident in their abilities and who is, moreover, afraid of failing at successfully completing a certain task. The procrastinator hereby creates the opportunity to blame possible failure on lack of effort instead of lack of ability, and at the same time anxiety related to the said task is postponed.

Corresponding to the results, it was not surprising that students with high self-efficacy have high intrinsic motivation and would be more likely to keep a persistent effort to accomplish the tasks. Conversely, the students with low self-efficacy would be unfocused on their academic goals, lack of initiative, dependent on others or group, and tend to do procrastination. If a student lacks initiative, he or she was inclined to rely on external motivation (e.g., reward) and lack a certain drive for accomplishing assignments on time. Moreover, low self-efficacy also triggered academic procrastination caused by hesitation to take an initiative for starting to do the tasks. Thus, academic self-efficacy was determined by students' decision, whether they would be fight or flight for finishing their tasks, such as individual assignments, group assignments, midterms, and final exams.

Students who procrastinate may have thoughts or behaviors that inhibit their ability to self-regulate, for example, false estimates of time needed to complete a study task and low self-efficacy (Lay \& Schouwenburg, 1993). Academic procrastination is a multidimensional construct with behavioral, cognitive, and affective components. Academic procrastination in college students demonstrates a lack of self-control and, when combined with lower selfefficacy for academics, can lead to lower academic achievement (A. Bandura, 1997).

Besides, Elias and Loomis, (2002) note that students with low self-efficacy are more tendencies to get involved in the problems of procrastination, and absence from lectures, delinquency, and study failure. Also, this finding is consistent with the result of Klassen, Krawchuk, and Rajani (2008) they state that self-efficacy is considered to be a strong indicator on procrastination. This finding also matches the finding of Sexton and Tuckman (1991). He found that there is an inverse correlation statistically significant difference between academic procrastination and self-efficacy. Haycock, McCarthy, and Skay (1998) also found that students with high self-efficacy are less tendency to procrastinate.

Interest in reducing delay is related more to self-perceived ability to handle tasks than to time spent procrastinating or reasons given for procrastinating. Studies demonstrated that procrastination has a relation with high levels of stress, low self-esteem, low self-efficacy, self-denigration, lower level of resourcefulness, higher levels of self-consciousness, selfhandicapping, and depression (Tamini \& Minakhany, 2008). Moreover, Solomon and Rothblum (1994) found that both fear of failure and feeling the task at hand to be disagreeable caused procrastination. In the case of fearing failure, procrastination has been explained by traits such as perfectionism, anxiety, and low self-efficacy beliefs regarding one's skills in organizing and regulating oneself in order to succeed at specific tasks (e.g., Bandura, 1997). Experiencing a task as disagreeable has been explained by problems in time management. Fear of failure, low self-efficacy beliefs, task aversiveness, and laziness have all been repeatedly mentioned as factors leading to procrastination (W. V. Eerde, 2003; Ferrari \& Tice, 2000; Pychyl et al., 2000; Rothblum et al., 1986)

Taking everything into account, it can be noted that in order to successfully regulated their academic life, a higher education student should be more self-efficacious in his belief about his/her academics and the ability the direct his/her academic life.

\section{CONCLUSION AND SUGGESTIONS}

Based on the result of this research it can be concluded that the students of $7^{\text {th }}$ 
semester had different procrastination level. The highest frequency of students' academic procrastination was in high level. It means that that the students mostly had a high level of academic procrastination. In contrast, the result of self-efficacy scale reveals that students of $7^{\text {th }}$ semester had low self-efficacy level. The main reasons of students' procrastination in academic life were lack of time management, task assertiveness, lack of sincerity, and bad personal initiative. The other reasons of the students' procrastination based on the group discussion were fear of failure as they set high expectation for the result, lack of motivation, excessive perfectionism as they set very high standard for the result, lack of focus so they could easily get distracted by other people or things, and felt unclear about how to get started the task.

Referring to the analysis of correlational study, the relationship between student's procrastination (as measured by the Procrastination Assesment Scale Student-PASS) and self-efficacy (as measured by the Self-Efficacy Scale) was investigated using Pearson product-moment correlation coefficient. Preliminary analyses were performed to ensure no violation of the assumptions of normality and linearity. There was a strong, negative correlation between the two variables, $r=-.651, n=130, p<.0005$, with high levels of students' procrastination associated with lower levels of self-efficacy belief. It means that the students who have low self-efficacy tend to procrastinate more in their academic life.

There are several suggestions that comes up as the result and implications of the present study's findings, the first suggestions is the lecturer needs to provide a choice of acceptable assignments for the students and ask them to choose one that become the students' interest. It would be better to develop assignments that provide the students with opportunities to develop career-relevant knowledge and skills. Moreover, the lecturers should also set clear norms and remind the students about the result expectations. They need to control the students by reminding them of upcoming deadlines. It can help the students to develop their time management skill because the students can see frequent reminding as a way to keeping on the schedule.

However, the present study is limited in investigating the level and reasons of academic procrastination, also the correlation between academic procrastination and selfefficacy. Academic procrastination may vary with such factors as age, gender, work experience, etc. Therefore, further investigation with different variables and a wider range of samples with varies levels would be highly suggested to be recommended to support and build up the findings.

\section{ACKNOWLEDGEMENT}

The writer's gratitude goes to several parties. First and foremost, the rector, the director of post graduate program and the head of English post graduate program of Ganesha University of Education who facilitated him to accomplish this research.

The writer's sincerest appreciations go to Prof. Dr. Ni Nyoman Padmadewi, M.A., and Dr. Dewa Putu Ramendra, S.Pd., M.Pd. whose patience, expertise, encouragement and gentle guidance have helped the writer to learn a lot of valuable knowledge during the completion of this article. the writer's would like also to convey his thankfulness to the students who willingly participated in this study.

\section{REFERENCES}

Ackerman, D. S., \& Gross, B. L. (2005). My Instructor Made Me Do It: Task Characteristics of Procrastination. Journal of Market Education, 27(1), 5-13.

AIQudah, M. F., Alsubhien, A. M., \& Heilat, M. Q. AL. (2014). The Relationship between the Academic Procrastination and Self-Efficacy among Sample of King Saud University Students. Journal of Education and Practice, 5(16), 101-112.

Argiropoulou, M., \& Ferrari, J. R. (2014). Frequency and Reasons for Academic Procrastination among Greek University Students : Shedding Light on a Darkened yet Critical Issue. PSYCHOLOGY, 21(2), 150-160.

Bakar, Z. A., \& Khan, M. U. (2016). Relationships Between Self-Efficacy and the Academic Procrastination Behaviour Among University Students in Malaysia: A General Perspective. Journal of Education and Learning, 10(3), 265-274. 
Balkis, M., \& Duru, E. (2017). Gender Differences in the Relationship between Academic Procrastination, Satifaction with Academic Life and Academic Performance. Electronic Journal of Research in Educational Psychology, 15(41), 105-125.

Bandura, A. (1995). Comments on the Crusade Against the Causal Efficacy of Human Thought. Journal of Behavior Therapy and Experimental Psychiatry, 26(3), 179-190.

Bashir, L. (2019). Social Networking Usage, Academic Procrastination and Performance Among University Students: Role of Self Efficacy and Metacognitive Beliefs. In Unpublished PhD. Lovely Professional University.

Bashir, Liyaqat. (2019). Social Networking Usage, Academic Procrastination and Performance Among University Students: Role Of Self Efficacy and Metacognitive Beliefs. Lovely Professional University.

Beck, Brett L., Koons, S. R., \& Milgrim, D. L. (2000). Correlates and Consequences of Behavioral Procrastination: The Effects of Academic Procrastination, SelfConsciousness, Self-Esteem and Self-Handicapping. Journal of Social Behavior and Personality, 15(5), 3-13.

Bekleyen, N. (2017). Understanding the Academic Procrastination Attitude of Language Learners in Turkish Universities. Educational Research and Reviews, 12(3), 108-115. https://doi.org/10.5897/ERR2016.3122

Beswick, G., Rothblum, E. D., \& Mann, L. (1988). Psychological Antecedents to Student Procrastination. Australian Psychologist, 23, 207-217.

Chow, H. P. H. (2011). Procrastination Among Undergraduate Students: Effects of Emotional Intelligence, School Life, Self-Evaluation, and Self- Efficacy. Alberta Journal of Educational Research, 57(2), 234-240.

Clark, J. L., \& Hill, O. . (1994). Academic Procrastination among African-American College Students. Psychological Reports, 75, 931-936.

Elias, S. M., \& Loomis, R. J. (2002). Utilizing Need for Cognition and Perceived Self-efficacy to Predict Academic Performance. Journal of Applied Social Psychology, 32, 16871702.

Ellis, A., \& Knaus, W. J. (1977). Overcoming Procrastination (Vol. 28, Issue 4). NY: Institute for Rational Living.

Ferrari, J. R., \& Tice, D. M. (2000). Procrastination As a Self-Handicap for Men And Women: A Task-Avoidance Strategy in a Laboratory Setting. Journal of Research in Personality, 34, 73-83.

Haycock, L. A., McCarthy, P., \& Skay, C. L. (1998). Procrastination in College Students: The Role of Self-Efficacy and Anxiety. Journal of Counseling and Development, 76, 317324.

Khan, M. J., Arif, H., Noor, S. S., \& Muneer, S. (2015). Academic Procrastination among Male and Female University and College Students. FWU Journal of Social Sciences, 8(5), 65-70. https://doi.org/10.1016/j.sbspro.2013.09.153

Klassen, R. M., Krawchuk, L. L., \& Rajani, S. (2008). Academic procrastination of undergraduates: Low self-efficacy to self-regulate predicts higher levels of procrastination. Contemporary Educational Psychology, 33(4), 915-931. https://doi.org/10.1016/j.cedpsych.2007.07.001

Malkoç, A., \& Mutlu, A. K. (2018). Academic Self-efficacy and Academic Procrastination: Exploring the Mediating Role of Academic Motivation in Turkish University Students. Universal Journal of Educational Research, 6(10), 2087-2093. https://doi.org/10.13189/ujer.2018.061005

Mandap, C. M. (2016). Examining the Differences in Procrastination Tendencies among University Students. International Journal of Education and Research, 4(4), 431-436. 
Miles, M. B., Huberman, A. M., \& Saldana, J. (2014). Qualitative Data Analysis (3rd ed.). SAGE Publications, Inc.

Özer, B. U., \& Saçkes, M. (2011). Effects of academic procrastination on college students' life satisfaction. Procedia - Social and Behavioral Sciences, 12, 512-519. https://doi.org/10.1016/j.sbspro.2011.02.063

Pychyl, T. A., Lee, J. M., Thibodeau, R., \& Blunt, A. (2000). Five Days of Emotion: An Experience Sampling Study of Undergraduate Student Procrastination. Journal of Social Behavior and Personality, 15, 239-254.

Rothblum, E. D., Solomon, L. J., \& Murakami, J. (1986). Affective, Cognitive, and Behavioral Differences Between High and Low Procrastinators. Journal of Counseling Psychology, 33, 387-394.

Saddler, C. D., \& Buley, J. (1999). Predictors of Academic Procrastination in College Students. Psychological Reports, 84, 686-688. https://doi.org/10.1016/i.sbspro.2013.12.112

Schouwenburg, H. C. (1993). Procrastinators and Fear of Failure: An Exploration of Reasons for Procrastination. European Journal of Personality, 6, 225-236.

Schraw, G., Wadkins, T., \& Olafson, L. (2007). Doing the Things We Do: A Grounded Theory of Academic Procrastination. Journal of Educational Psychology, 99(1), 12-25. https://doi.org/10.1037/0022-0663.99.1.12

Sexton, T. L., \& Tuckman, B. W. (1991). Self-Beliefs and Behavior: The Role of Self-Efficacy and Outcome Expectation Over Time. Personality and Individual Differences, 12(7), 725-736. https://doi.org/10.2478/linpo-2018-0006

Solomon, L J., \& Rothblum, E. D. (1994). Procrastination Assessment Scale-Student (PASS). In J. Fischer \& K. Corcoran (Eds.), Measures for Clinical Practice (Vol. 2, pp. 446-452). The Free Press.

Solomon, Laura J., \& Rothblum, E. D. (1984). Academic procrastination: Frequency and cognitive-behavioral correlates. Journal of Counseling Psychology, 31(4), 503-509. https://doi.org/10.1037//0022-0167.31.4.503

Tamini, B. K., \& Minakhany, G. (2008). Academic procrastination and its relationship with self-esteem and Life satisfaction. Journal of Psychology, 7(august), 87-104.

Van Eerde, Wendelien. (2003). Procrastination at work and time management training. Journal of Psychology: Interdisciplinary and Applied, 137(5), 421-434. https://doi.org/10.1080/00223980309600625

Watson, D. C. (2001). Procrastination and The Five-Factor Model: A Facet Level Analysis. Personality and Individual Differences, 30, 149-158.

Yilmaz, M. . (2017). The Relation between Academic Procrastination of University Students and Their Assignment and Exam Performances: The Situation in Distance and FaceTo-Face Learning Environments. Journal of Education and Training Studies, 5(9), 146157. https://doi.org/10.1016/i.sbspro.2015.02.013 